\title{
Visions Making Sense of the Present and Co-Creating the Future
}

\author{
Christopher Coenen
}

Published online: 14 March 2017

C Springer Science+Business Media Dordrecht 2017

In the late 1950s, C.P. (Charles Percy) Snow famously stated that "[i]f the scientists have the future in their bones, then the traditional culture responds by wishing the future did not exist" ([1], 11). By "traditional culture" he meant novelists and writers in the humanities. This dualism was questionable from the start, however; nowadays the notion that (natural) scientists tend to express futuristic views while representatives of "traditional culture" wallow in the past and peer anxiously into the future seems more implausible than ever. Many natural scientists and engineers either appear to doubt whether lofty visions that equate technoscientific advances with human progress are justifiable, or hesitate to express such visions so as not to give (organised civil) society reason to fear that they may be suffering from delusions of technoscientific grandeur. On the other hand, certain social scientists and humanities scholars articulate very optimistic visions of the future of science, technology and society in line with the extremely progressivist traditions of nineteenth century sociology (for example in Positivism). Moreover, many philosophers, humanities scholars and social scientists who are sceptical about such optimistic visions have come to realise since the 2000s that far-reaching visions of the future play a crucial role in discussions on science, technology and society of our times.

C. Coenen $(\bowtie)$

Institute for Technology Assessment and Systems Analysis (ITAS), Karlsruhe Institute of Technology (KIT), POB 3640, 76021 Karlsruhe, Germany

e-mail: christopher.coenen@kit.edu
In light of these developments, I am delighted that my colleagues Martin Sand and Christoph Schneider have guest-edited a special section of our journal dedicated to a wide variety of practises that can be seen as contributing to processes of "visioneering". This concept was introduced by the historian Patrick McCray, most prominently in his 2013 book The Visioneers: How a Group of Elite Scientists Pursued Space Colonies, Nanotechnologies, and a Limitless Future [2]. In McCray's view, which is explained in more detail in Sand's and Schneider's introduction to the special section, visioneering is a diverse set of activities conducted by forward-looking thinkers with a background in natural science or technology and aimed at developing and promoting an encompassing vision of the future of science, technology and society. As McCray and other authors such as Joachim Schummer [3, 4] have pointed out, many discussions about technoscience and the future that have taken place since the 1980s, including those about nanotechnology, have been shaped to a major extent by a specific technofuturistic approach that can be deemed "transhumanist" - the term most frequently used to describe this approach in the present decade. The rise or rather resurgence [5] of this approach has posed a challenge for studies on new and emerging technologies since the late 1990 s, with the result that existing theoretical approaches in technology assessment - and in science and technology studies more generally have been refined and new ones developed. It has become obvious that the creation and use of radical and farreaching visions of the future in discourse on research and technology development are themselves activities 
that require reflection on responsibility in research, innovation and science policy [6]. As Laura Cabrera [7] has emphasised, being a visioneer entails a high degree of social responsibility, as visioneers play an important role in social change, influencing attitudes, perceptions and funding policies. Arguably, we need historically informed, culturally diverse and more participatory deliberation on visions concerning the future of science, technology and society [8].

The special section guest-edited by Sand and Schneider advances the study of future visions in science and technology discourse both conceptually and empirically. The authors of the articles analyse the roles of future visions and of visioneering efforts in such diverse socio-technical fields, processes and issues as energy systems (Franziska Engels, Anna Verena Münch and Dagmar Simon; Urte Brand and Arnim von Gleich; Arianna Ferrari and Andreas Lösch), food systems (Ferrari and Lösch; Niklas Gudowsky and Mahshid Sotoudeh), ageing in urban environments (Gudowsky and Sotoudeh), Web 2.0 and 3D printing (Sascha Dickel and Jan-Felix Schrape), and Industry 4.0 (Sabine Pfeiffer). They look not only at well-established topics such as energy policies but also at emerging discussions of issues such as in vitro meat. The introduction by Sand and Schneider touches upon the many facets of recent and current visioneering processes, as indeed do the articles themselves. Although for reasons relating to my own biographical background I was particularly fascinated by Dickel's and Schrape's illuminating analysis of media technology futures as forms of utopian communication, all articles do a very fine job of expanding the scope of studies on the role of future visions in science and technology discourse. Moreover, the present issue contains a book review that ties in perfectly with the special section's topic: Rosangela Barcaro discusses Federica Lucivero's study of the ethical assessment of emerging technologies, in which Lucivero focuses on the moral plausibility of technological visions.

I am also delighted that the present issue features an article by Simone Arnaldi which addresses a problem that is about to seriously hamper regulatory and other governance activities concerning science, technology and innovation: the dearth of studies into the factors that affect compliance with soft regulation measures. This is a very timely analysis given the much increased relevance of soft regulation in science and technology policies. Arnaldi not only develops a taxonomic scheme that highlights the mechanisms affecting compliance with soft regulation, but also applies this scheme in an indepth analysis of the views of a group of scientists and company managers in the Italian nanotechnology sector. Notably, he argues that the role played by intermediary organisations in the diffusion and acceptance of soft regulatory instruments deserves much greater attention.

As you may already have noticed, our journal's Editorial Board has seen a number of changes. I am extremely grateful that Bernadette Bensaude Vincent, Christopher Bosso, Frans Brom, Armin Grunwald, Harro van Lente, Sabine Maasen, Ruud ter Meulen, Andy Miah, René von Schomberg and Gregor Wolbring have all agreed to join the board, and would like to take this opportunity to express warmest thanks, also on behalf of our founding editor John Weckert, to all past and present board members for their support of the journal. Furthermore, I am very much looking forward to working with a new member of our Editorial Team: Martin Mullins heads the Department of Accounting \& Finance at the University of Limerick's Kemmy Business School; his excellent expertise in the risk and innovation aspects of nanotechnology - and in many other areas - will benefit the journal enormously.

I hope you find reading this new issue of NanoEthics. Studies of New and Emerging Technologies interesting and rewarding - and hope that all your optimistic visions of the future come true.

\section{References}

1. Snow CP (1959) The two cultures and the scientific revolution. Cambridge University Press, New York

2. McCray P (2013) The visioneers: how a group of elite scientists pursued space colonies, nanotechnologies, and a limitless future. Princeton University Press, Princeton

3. Schummer J (2004) Societal and ethical implications of nanotechnology: meanings, interest groups, and social dynamics. Techné 8(2):56-87

4. Schummer J (2009) Nanotechnologie. Spiele mit Grenzen. Suhrkamp (edition unseld), Frankfurt

5. Coenen C (2014) Transhumanism in emerging technoscience as a challenge for the humanities and technology assessment. Teorija in praksa 51(5):754-771

6. Grunwald A (2016) The hermeneutic side of responsible research and innovation. Isten, London

7. Cabrera Trujillo LY (2014) Visioneering and the role of active engagement and assessment. NanoEthics 8(2):201-206

8. Coenen C (2010) Deliberating visions: the case of human enhancement in the discourse on nanotechnology and convergence. In: Kaiser M, Kurath M, Maasen S, Rehmann-Sutter C (eds) Governing future technologies. Nanotechnology and the rise of an assessment regime. Springer, Dordrecht, pp 73-87 